\title{
Magnitude and factors associated with anti-malarial self-medication practice among residents of Kasulu Town Council, Kigoma-Tanzania
}

\author{
Stanley Mwita ${ }^{1}$, Omary Meja ${ }^{1}$, Deogratias Katabalo ${ }^{1}$, Catherine Richard ${ }^{2}$
}

1. School of Pharmacy, Catholic university of Health and Allied Sciences, Mwanza, Tanzania.

2. Kasulu District Council, Kigoma, Tanzania.

\section{Emails:}

OM:sm.omary@yahoo.com; DK:dkatabalo@gmail.com; CR: crugarabamu@yahoo.com

\begin{abstract}
:
Background: Anti- malarial self-medication practice in Africa is very common. It is considered as an alternative way for people who cannot afford the cost of health care services. This study was conducted to assess the magnitude and factors associated with anti-malarial self-medication practice among residents of Kasulu Town Council.

Materials and methods: The study was a descriptive cross sectional study. Two hundred and eighty consenting respondents were selected by systematic random sampling and interviewed with the aid of a semi structured questionnaire to assess anti-malarial self- medication practice. A p value of less than 0.05 was considered statistically significant, at $95 \%$ confidence interval.

Results: Prevalence of anti-malarial self-medication was (69.6\%). Majority of the respondents $(83.1 \%)$ reported that, they did not get better after self- medication. About $36 \%$ of the respondents metioned time taken in health facilities as the main factor for self- medication.

Conclusion: This study revealed that, self-medication practice is very common among community members in Kasulu district. The main reasons identified for self-medication was long time taken to get treatment in health facilities.
\end{abstract}

Keywords: Anti-malarial, Self- medication, Practice, Kasulu, Tanzania.

DOI: https://dx.doi.org/10.4314/ahs.v19i3.20

Cite as: Mwita S, Meja O, Katabalo D, Richard C. Magnitude and factors associated with anti-malarial self-medication practice among residents of Kasulu Town Council, Kigoma-Tanzania. Afri Health Sci 2019;19(3): 2457-2461. https:/ / dx.doi.org/10.4314/abs.v19i3.20

\section{Introduction}

Self-medication can be defined as "the taking of drugs, herbs or home remedies on one's own initiative, or on the advice of another person, without consulting a prescriber ${ }^{1}$. Self- medication is practiced world-wide, in some cases it is an alternative way for people who cannot afford the cost of health care services ${ }^{2}$. Medicines which are commonly used for self-medication include analgesics, anti-malarials, antibiotics and cough syrups ${ }^{3}$. Perception
Correspondence author:
Stanley Mwita,
Catholic University of Health and Allied
Sciences, Mwanza, Tanzania
School of Pharmacy
Msc Pharm Management
P.O.Box 1464, Mwanza-Tanzania
Phone: +255 786671071
Email: stanleymwita@gmail.com

of illness is one of the factors that has increased the prevalence of self-medication, which accounts for about 2.9 $-3.7 \%$ causes of death in hospitals as a result of drugdrug interactions ${ }^{4}$. The variation in the prevalence of self-medication among developing and developed nations can be caused by disparities in health care systems such as reimbursement policies, access to health care, and drug dispensing policies ${ }^{5}$.

Malaria is still of public health concern in sub-Saharan Africa where over 500 million episodes of malaria occur yearly, predominantly in children under five years of age, resulting in the death of approximately a million of these children ${ }^{6}$. Antimicrobial resistance and the development of parasite resistance to anti-malarial drugs that has been reported in several countries are likely to be associated with irrational use of antibiotics and anti-malarial drugs ${ }^{7,8}$. Anti- malarial self-medication practice in sub Saharan Africa, Tanzania in particular is very common. People are treating themselves with any medicine or any

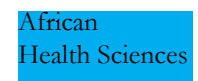

(C) 2019 Mwita et al. Licensee African Health Sciences. This is an Open Access article distributed under the terms of the Creative commons Attribution License (https://creativecommons.org/licenses/BY/4.0), which permits unrestricted use, distribution, and reproduction in any medium, provided the original work is properly cited. 
substance they may think of without considering its toxic or harmful effects which may arise ${ }^{9}$. Analysis of reasons for self-medication revealed that, $25 \%$ felt that the illness was too mild and did not require the services of a doctor $^{10}$. It was also observed that, $19 \%$ of the respondents had previous experience in treating a similar condition and believed that, even if they went to the doctor they would be prescribed similar medicines ${ }^{10}$.

The abuse of anti-malarial self-medication has resulted in people delaying to seek hospital intervention, thereby complicating their illnesses, self-medication may treat the symptoms but not the underlying disease since there are some diseases like typhoid which have similar symptoms to malaria ${ }^{11}$. Socio-cultural, poverty, lack of knowledge on the impact of self-medication, previous experience with similar symptoms, high charges by hospitals, lack of time to go to the health facility, lack of accessibility to health care facility, distance to the heath facility, urgency of the problem, bureaucracy, overcrowding in hospitals, stock outs of drugs in most public health facilities and minor illnesses are the factors associated with self-medication ${ }^{2,12}$. Self-medication with anti-malarial drugs has been widely practiced in different countries including Tanzania ${ }^{13,14}$. The individual's chronological age, level of formal education and occupation are determinants of the knowledge on malaria while gender, level of formal education and individual's occupation are factors that influence self-medication ${ }^{15}$. Currently, there are few studies on self-medication practice which have been conducted in Tanzania. Therefore this study aims to assess factors and magnitude of anti-malarial self-medication at Kasulu Town Council Kigoma-Tanzania.

\section{Methodology}

\section{Study design}

A descriptive cross sectional study was designed to capture quantitative data.

\section{Study setting}

The study was conducted in randomly selected household of Kasulu District. This district is one of the six districts of the Kigoma Region of Tanzania. It is bordered to the north by Burundi, to the east by Kibondo District, to the south by Uvinza District, to the west by Kigoma District and to the northwest by Buhigwe District. According to the 2012 Tanzania National Census ${ }^{16}$, the population of the Kasulu Town Council was 225,660. Kasulu Town
Council is predominantly occupied by the "Waha" ethnic group. It comprises 108 streets and 15 wards. The study was conducted between April and August 2016.

\section{Sampling and data collection}

The sample size was 280 households which were calculated using Kish Leslie formula (Proportion of self- medication being $76 \%$ ). Systematic random sampling was used to select household and only one head of the family available at the time of the study was interviewed about self-medication history of any family member aged above 6 years of age who suffered from malaria six months prior the date of the interview .

We adopted the method used by Awad et $\mathrm{al}^{2}$, semi-structured questionnaire consisted of both open-ended and closed ended questions was used to assess anti-malarial self- medication practice among the community members. The questionnaire was used to collect information about the magnitude of self-medication practice and factors associated with anti-malarial self-medication practice. The questionnaire prepared in English and then translated into Swahili, which is the most widely spoken language of the community.

\section{Data analysis}

All the collected data were counter-checked for their clarity and validity. The coded data were analyzed using Statistical Package for Social Sciences (Version 20.0) computer analysis software. Prevalence and factors associated with self-medication in the community were reported as percentage. A p value of less than 0.05 was considered as statistically significant, at 95\% confidence interval.

\section{Ethical consideration}

Ethical clearance was sought from the Ethical Review Board of the Catholic University of Health and Allied Sciences (CUHAS) and from District Executive Director of Kasulu. Participants were asked for consent before the interview.

\section{Results \\ Demographic characteristics of respondents}

The respondents mean age was 30.6 and ranged between 18-64 years. Out of the 280 subjects interviewed, males were $10 \%$ (28) while females were $90 \%$ (252). Those who did not attend any formal education were $4.3 \%$ (12) and tertiary level were $3.9 \%$ (11). 
Table 1: Demographic characteristics of respondents

\begin{tabular}{llll}
\hline Variable & & Frequency (n) & Percentage (\%) \\
\hline Mean age= 30.6 ranged between 18 and 64 years & 280 & \\
Sex & Male & 28 & 10 \\
& Female & 252 & 90 \\
Educational background & No education & 12 & 4.3 \\
& Primary & 205 & 73.2 \\
& Secondary & 52 & 18.6 \\
& Tertiary & 11 & 3.9 \\
& & & \\
Occupation & Employed & 140 & 50 \\
& Unemployed & 140 & 50 \\
\hline
\end{tabular}

Magnitude of anti-malarial self-medication practice $\quad 69.6 \%$; among the respondents who practiced self-mediThe prevalence of anti-malaria self -medication was cation, $83.1 \%$ did not improve.

Table 2: Magnitude of anti-malaria self-medication

\begin{tabular}{llll}
\hline Variable & & Frequency (n) & Percentage (\%) \\
\hline $\begin{array}{l}\text { Ever given } \\
\text { anti-malaria } \\
\text { medicine }\end{array}$ & Yes & 195 & 69.6 \\
$\begin{array}{l}\text { without } \\
\text { prescription }\end{array}$ & 85 & 30.4 \\
Health & Improve & 32 & \\
outcome after & Did not & 162 & 16 \\
improve & & 83 \\
un-prescribed & Frequently & 118 & 1 \\
medicine & Occasionally & 58 & 60.5 \\
$\begin{array}{l}\text { Frequency of } \\
\text { using }\end{array}$ & Rarely & 19 & 29.7 \\
$\begin{array}{l}\text { anti-malarial } \\
\text { without }\end{array}$ & & & \\
prescription & & & \\
\hline
\end{tabular}


Factors influencing anti-malarial self-medication practice Majority of respondents $(36.4 \%)$ mentioned time taken at health facility as the main factor for self- medication.

Table 3: Factors influencing anti-malaria self-medication practice

\begin{tabular}{lll}
\hline Factor & Frequency (n) & Percentage (\%) \\
\hline Emergency illness & 44 & 22.5 \\
Distance to health facility & 20 & 10.3 \\
Proximity of pharmacy shop & 40 & 20.5 \\
Takes time at health facility & 71 & 36.4 \\
No medicine in health facility & 20 & 10.3 \\
\hline
\end{tabular}

\section{Magnitude of anti-malarial self-medication based on social-demographics}

Majority of females $(70.2 \%)$, Uneducated $(91.7 \%)$ and unemployed $(73.6 \%)$ practiced self-medication.

Table 4: Demographic factors associated with self -medication

\begin{tabular}{lllll}
\hline & Factor & \multicolumn{2}{l}{$\begin{array}{l}\text { Used un-prescribed } \\
\text { medicine }\end{array}$} & p-value \\
& & Yes & No & \\
\hline Sex & Male & $18(64.3 \%)$ & 10 & 0.516 \\
& Female & $177(70.2 \%)$ & 75 & \\
Educational & Uneducated & $11(91.7 \%)$ & 1 & \\
background & Primary & $148(72.2 \%)$ & 57 & \\
& Secondary & $32(61.5 \%)$ & 20 & 0.013 \\
& Tertiary & $4(36.4 \%)$ & 7 & \\
& & & & 0.153 \\
Occupation & Employed & $103(73.6 \%)$ & 37 & \\
& Unemployed & $92(65.7 \%)$ & 48 & \\
\hline
\end{tabular}

\section{Discussion}

This study was conducted to assess the magnitude and factors associated with anti-malarial self-medication practice among residents of Kasulu town Council. The prevalence of anti-malarial self-medication in Kasulu is high, more than two third of the population. This finding is similar to that of a study done in Dar-es-Salaam, Tanzania where the prevalence for anti-malaria self-medication was $71.7 \%$ (13). Another study conducted in Kenya found that about three quarter of the participants reported self-medication for perceived malaria illness ${ }^{17}$. In this study, it was found that more than eighty percent of re- spondents who used anti-malarials without prescription did not get any improvement. This implies that, possibly they were suffering from other diseases with similar symptoms as malaria. Treatment seeking behavior for malaria in sub-Saharan Africa is complex, usually depending on the local health system, society and culture ${ }^{18}$.

From this study it was revealed that the level of education is significantly related to self- medication where more than 90\% (Table 4) of uneducated respondents were found to use anti-malarial without prescriptions. This finding is in line with results reported by Awad et al in 2005 who found that, less educated respondents were more likely to use anti-malaria without prescriptions ${ }^{2}$.

African Health Sciences Vol 19 Issue 3, September, 2019 
There are several factors that contribute to self-medication. The current study found that, the main factor for self-medication was the time taken at health facilities (Table 3). Proximity to the drug shops and out of stock of anti-malaria in health facilities were other factors mentioned to contribute the use of medicines without prescription. Studies found that, factors influencing self-medication include the perception that drug shops are comparatively cheaper than other health care facilities, which charge consultation and laboratory fees ${ }^{12}$. Also, patients who had previous experience with similar ailments have confidence to use medicines without prescriptions ${ }^{2}$.

\section{Conclussion}

This study revealed that, self-medication practice is very common among community members in Kasulu district. The main reasons identified for self- medication was long time taken to get treatment in health facilities. Level of education was found to be associated with self-medication, thus there is a need to create awareness to the rural community especially to the less educated group on the potential risks of self-medication.

\section{Conflict of interest}

Authors declare no conflict interests.

\section{Authors' contributions}

SM,DK and CR designed the study; CR collected the data; OM and CR analyzed the data; SM and DK drafted the first manuscript; SM and OM critically reviewed the manuscript.

\section{References}

1. Hernandez-Juyol M, Job-Quesada J. Dentistry and self-medication: A current challenge. Med Oral. 2002;7:344-7 PubMed .

2. Awad A, Eltayeb I, Matowe L, Thalib L. Self-medication with antibiotics and antimalarials in the community of Khartoum State, Sudan. J Pharm Pharm Sci. 2005;8:32631 PubMed.

3. Afolabi A. Factors influencing the pattern of self-medication in an adult Nigerian population Ann Afr Med. 2000;7(3):120 PubMed -7.

4. Erhun WO, Erhun M. The qualitative impact of broadcasting media advertisement on the perception of medicines in Nigeria. Journal of Consumer Behavior. 2002;3(1):819.

5. Braithwaite A, Pechere J. Pan-European survey of pa- tients' attitudes to antimicrobial drugs and antibiotics. $J$ Int Med Res. 1996;24(4):229-36.

6. Owusu-Agyei S, Asante K.P, Adjuik M, Adjei G, Awini E, Adams M, et al. Epidemiology of malaria in the forest-savanna transitional zone of Ghana. Malaria Journal. 2009;8:220.

7. Kotwani A, Wattal C, Joshi PC, Holloway K. Irrational use of antibiotics and role of the pharmacist: An insight from a qualitative study in New Delhi, India. J Clin Pharm Ther. 2012;37:308-12 PubMed.

8. Combie M. Self-treatment for malaria: the evidence and methodological issues. Health Policy Plan. 2002;17:333-44 PubMed .

9. Tillement J, Delaveau P. Self-medication and safety Bulletin de 1Academie nationale de medicine. 2007;191(8):1517-26.

10. Shankar P.R, Partha P, Shenoy N. Self-medication and non-doctor prescription practices in Pokhara Valley, Western Nepal: a questionnaire-based study. BMC Family Practice. 2001;3:17.

11. Yousef A, Bakri M, Bustanji A, Wazaify M. Self-medication patterns in Amman, Jordan. Pharmacy world science. 2008;30(1):24-30.

12. Gupta P, Bobhate P, Shrivastava SR. Determinants of self medication practices in an urban slum community. Asian Journal of Pharmaceutical and Clinical Research. 2011;4(3):3-6.

13. Mnyika KS, Killewo JZ, Kabalimu. T. Self-medication with antimalarial drugs in Dar es Salaam, Tanzania. Trop Geogr Med. 1995;47(1):32-4.

14. Nsimba SED, Rimoy G. Self-medication with chloroquine in a rural district of Tanzania: a therapeutic challenge for any future malaria treatment policy change in the country. J Clin Pharm Ther. 2005;30: 515-9 PubMed . 15. Kigodi K, Komanya M. Malaria and anti-malarial drugs utilisation among adults in a rural coastal community of Tanzania: knowledge, attitude and practice study. Dar es salam Medical Students Journal. 2006 14(1).

16. URT. 2012 Population and Housing Cencus, population distribution by administrative areas. In: statistics NBo, editor. Dar es salaam, 2013.

17. Kimoloi S, Okeyo N, Ondigo B, Langat BK. Choice and Sources of Antimalarial Drugs Used for Self-medication in Kisumu, Western Kenya. Afr J Pharmacol Ther. 2013;2(4) 124 PubMed -9.

18. McCombie S. Self-treatment for malaria: the evidence and methodological issues. Health Policy Plan. 2002; 17:17:333 PubMed -44. 